\title{
AS CIDADES DE HOJE : DESAFIOS AOS ENFERMEIROS ESPECIALISTAS EM ENFERMAGEM DE REABILITAÇÃO PARA A INCLUSÃO
}

\section{LAS CIUDADES DE HOY: DESAFIOS PARA LOS ENFERMEROS DE REHABILITACIÓN PARA LA INCLUSIÓN}

TODAY'S CITIES: CHALLENGES FOR REHABILITATION NURSES FOR INCLUSION

DOI 10.33194/rper.2020.v3.n2.1.5766 | Submetido 11/04/2020 | Aprovado 15/12/2020

\section{Ana Isabel Ribeiro da Silva Pereira ${ }^{1}$; ; Maria Manuela Martins ${ }^{1}$ (D); Rute Salomé Ribeiro da Silva Pereira ${ }^{2}$; Bárbara Pereira Gomes ${ }^{1}$ (D); João Santos ${ }^{3}$ (D) Paulo Alexandre Matos Cunha ${ }^{4,5}$ (D)}

1 - Escola Superior de Enfermagem do Porto; 2 - Instituto de Ciências Biomédicas Abel Salazar;

3 - Faculdade de Arquitetura da Universidade do Porto; 4 - Universidade Lusíada Porto;

5 - Faculdade de Direito da Universidade de Coimbra

\section{RESUMO}

As barreiras arquitetónicas provocam inacessibilidade do meio, contribuindo para a limitação da funcionalidade e criação de incapacidade.

Objetivos: Analisar as condições da acessibilidade na via pública face às necessidades das pessoas com mobilidade condicionada e compreender até que ponto os ambientes externos ao edificado contribuem para a inclusão social das pessoas com mobilidade condicionada.

Metodologia: Estudo quantitativo, observacional, descritivo, transversal, a partir de uma amostra não probabilística por escolha racional - 31 ruas (62 percursos pedonais), com recurso a uma grelha de avaliação ad hoc(1).

Resultados: Dos percursos pedonais avaliados, 75,8\% permitem o acesso e permanência de uma pessoa em cadeira de rodas, bem como o alcance frontal e lateral aos objetos dispostos na via, no entanto 22 ,6\% dos percursos não são acessivveis.

Conclusão: Apesar da legislação e políticas de acessibilidade vigentes continuam a subsistir barreiras arquitetónicas na via pública que influenciam diretamente a independência das pessoas com mobilidade condicionada, o que sugere que o enfermeiro de reabilitação deve desenvolver um trabalho efetivo junto dos municípios.

Palavras-chave: limitação da mobilidade, acessibilidade arquitetónica, enfermagem de reabilitação

\section{RESUMEN}

Las barreras arquitectónicas provocan la inaccesibilidad del medio ambiente, contribuyendo a la limitación de la funcionalidad y la creación de discapacidad.

Objetivos: Analizar las condiciones de accesibilidad en vías públicas en vista de las necesidades de las personas con movilidad reducida; comprender en qué medida los entornos externos del edificio contribuyen a la inclusión social de las personas con movilidad reducida;

Metodología: Estudio cuantitativo, observacional, descriptivo, transversal de una muestra no probabilística por elección racional - 31 calles (62 senderos peatonales) con cuadrícula de evaluación ad hoc (Decreto-Ley 163/2006) (1).

Resultados: el 75.8\% de los senderos peatonales evaluados permiten el acceso y permanencia de una persona en silla de ruedas y el alcance frontal y lateral a los objetos, sin embargo, el $22.6 \%$ de los caminos no son accesibles.

Conclusión: A pesar de las políticas de accesibilidad las barreras arquitectónicas continúan en el camino, influyendo la independencia de las personas con movilidad reducida, sugiriendo que los enfermeros de rehabilitación deben desarrollar un trabajo con los municipios.

Palabras clave: limitación de la movilidad; accesibilidad arquitectónica; enfermería de rehabilitación

\section{ABSTRACT}

The architectural barriers on public highway cause inaccessibility, contributing to the limitation of functionality and creation of disability.

Objectives: to analyze the conditions of accessibility on public highways in view of the needs of disabled people;

To understand how external environments contribute to the social inclusion of people with disabilities; 
Methodology: Quantitative, observational, descriptive, cross-sectional study from a non-probabilistic sample by rational choice - 31 streets (62 pedestrian paths), using an ad hoc evaluation grid (Decree-Law 163/2006) (1).

Results: $75.8 \%$ of the pedestrian paths evaluated allow access and permanence of a person in a wheelchair, as well as the frontal and lateral reach to objects placed on the road, however $22.6 \%$ of the paths are not accessible.

Conclusion: although the current legislation and accessibility policies, there are still architectural barriers on public highways that rehabilitation nurse directly influence the independence of disabled people, which suggests that should develop effective work with municipalities.

Keywords: mobility limitation; architectural accessibility; rehabilitation nursing

\section{INTRODUÇÃO}

0 enfermeiro especialista em enfermagem de reabilitação "capacita a pessoa com deficiência, limitação da atividade e/ou restrição da participação para a reinserção e exercício da cidadania"(2). Através dos seus conhecimentos legislativos e normas técnicas promotoras de integração participação cívica; capacidade de sensibilização da comunidade para práticas inclusivas; identificação e orientação para a eliminação de barreiras arquitetónicas e emissão de pareceres técnico-científicos, este promove a mobilidade, acessibilidade e participação social, o que nos leva a analisar a acessibilidade na via pública, local que todos os cidadãos com mobilidade condicionada atravessam.

Os Censos de 2011 revelam-nos que "cerca de 17,8\% (taxa de prevalência) da população com 5 ou mais anos de idade declarou ter muita dificuldade, ou não conseguir realizar, pelo menos, uma das 6 atividades diárias (ver, ouvir, andar, memória/concentração, tomar banho/ vestir-se, compreender/fazer-se entender)(3)", o que condiciona a mobilidade.

Segundo o Decreto-Lei 163/2006, que define o regime da acessibilidade aos edifícios e estabelecimentos que recebem público, via pública e edifícios habitacionais, as pessoas com mobilidade condicionada são "pessoas em cadeiras de rodas, pessoas incapazes de andar ou que não conseguem percorrer grandes distâncias, pessoas com dificuldades sensoriais, tais como as pessoas cegas ou surdas, e ainda aquelas que, em virtude do seu percurso de vida, se apresentam transitoriamente condicionadas, como as grávidas, as crianças e os idosos"(1).

Consultando os Censos, no município de Vila Nova de Famalicão, local da realização deste estudo, sabe-se que residem 133832 pessoas. Dessas, 1128 não conseguem andar/subir degraus e 9557 têm muita dificuldade em efetuar a ação; 1723 não conseguem tomar banho e ou vestir-se sozinho e 3470 têm muita dificuldade; 237 não conseguem ver e 9700 têm muita dificuldade; 220 não conseguem ouvir e 5185 têm muita dificuldade em efetuar a ação, dados que apontam para a necessidade de enfermeiros de reabilitação nesta área territorial. Na freguesia de Vila Nova de Famalicão residem 8478 pessoas. Dessas, 43 não conseguem andar/subir degraus e 390 têm muita dificuldade em efetuar a ação; 67 não conseguem tomar banho e ou vestir-se sozinho e 165 têm muita dificuldade; 22 não conseguem ver e 449 têm muita dificuldade; 9 não conseguem ouvir e 227 têm muita dificuldade em efetuar a ação(3). Face aos dados é importante compreender as condições da via em termos de acessibilidade, uma vez que a área analisada é o centro da cidade, com maior probabilidade de ser frequentada pelos munícipes.

No quotidiano, as pessoas com mobilidade condicionada vão-se confrontando com barreiras arquitetónicas. Estas impedem a ativa participação cívica, influenciam o seu desenvolvimento, a sua participação na comunidade e consequentemente a sua integração social. É fundamental que qualquer ambiente reúna todas as condições necessárias para uma integração total de qualquer indivíduo num ambiente acessível não demonstre qualquer tipo de dificuldade. Se continuarem a existir espaços públicos com barreiras arquitetónicas impeditivas da utilização dos mesmos por pessoas com mobilidade condicionada, não se pode falar numa sociedade inclusiva, dado que existe legislação que regulamenta as condições de acessibilidade, mas estas não se verificam(4).

As cidades, para serem acessíveis, devem permitir que todos se possam deslocar de forma igualitária, sem qualquer tipo de restrição participativa. Apesar da legislação acerca da acessibilidade ser ainda bastante recente, o Estado, por dever, é invocado a dar resposta à inacessibilidade do meio. As Autarquias têm também um papel ativo na "promoção, concretização e fiscalização de direitos fundamentais de todos os cidadãos em matéria de urbanismo, acessibilidade e mobilidade"(5).

O Decreto-Lei 163/2006 estipulou um prazo máximo de 10 anos para a adaptação de instalações, edifícios, estabelecimentos, equipamentos públicos e de utilização da via pública. Em outubro de 2017 foi publicada uma nova alteração ao Decreto-Lei, onde constava a criação de uma Comissão para a Promoção das Acessibilidades, com o objetivo de realizar o diagnóstico da situação atual das acessibilidades nos edifícios, instalações e espaços da administração central, local e institutos públicos que revistam a natureza de serviços personalizados e de fundos públicos. Neste sentido, seria expectável que em fevereiro de 2017 já não existissem barreiras arquitetónicas em locais de uso público. Assim, é impreterível perceber se o edificado do país cumpre ou não as normas da acessibilidade.

Ao compreender a extensão da problemática da inclusão e sendo uma condicionante da dimensão da acessibilidade arquitetónica, este estudo delimitar-seá exclusivamente à análise das barreiras arquitetónicas nas cidades. 
Estamos assim mediante três desafios para os enfermeiros especialistas em enfermagem de reabilitação, sendo o primeiro sugerir a abolição das barreiras arquitetónicas na área de influência das pessoas com mobilidade condicionada, ao acompanhar clinicamente essas pessoas, particularmente os novos casos, que se encontram neste enquadramento; o segundo, a necessidade de criar e desenvolver campanhas de sensibilização à população em geral, particularmente nas escolas, para o respeito e apoio sempre que necessário às pessoas com mobilidade condicionada e por último o treino das pessoas com mobilidade condicionada no cenário real para identificar as necessidades e auxiliar a ultrapassar as mesmas(6).

Surge, neste contexto, por forma a analisar as condições da acessibilidade de acordo com a legislação em vigor, a seguinte questão de investigação: será que as condições das vias públicas facilitam a acessibilidade das pessoas com mobilidade condicionada?

Este estudo pretende dar resposta aos seguintes objetivos: analisar as condições da acessibilidade na via pública face às necessidades das pessoas com mobilidade condicionada e compreender até que ponto os ambientes externos ao edificado contribuem para a inclusão social das pessoas com mobilidade condicionada.

Neste contexto, o presente estudo terá como finalidade contribuir para uma sociedade mais sensível para a inclusão das pessoas com mobilidade condicionada, ao ser pretendido tornar visível os problemas da via pública para as pessoas com mobilidade condicionada.

\section{METODOLOGIA}

Utilizamos uma metodologia quantitativa, observacional descritiva transversal. 0 estudo foi desenvolvido no município de Vila Nova de Famalicão, pertencente ao distrito de Braga, nomeadamente a freguesia de Vila Nova de Famalicão. A população- alvo é formada pelas 116 ruas pertencentes à referida freguesia. Devido à impossibilidade de se avaliar a totalidade das ruas, recorreu-se a uma amostragem não probabilística por escolha racional para determinar a amostra, uma vez que a seleção foi determinada entre a investigadora e representantes da Câmara Municipal, obtendo-se, assim, as ruas mais centralizadas e próximas a serviços públicos. Resultaram assim um total de 31 ruas, sendo avaliados ambos os lados das ruas, o que corresponde a $26.7 \%$ das possibilidades de análise.

0 método de colheita de dados utilizado foi a grelha de avaliação ad hoc, que consiste numa grelha de observação da acessibilidade da via pública, baseada na legislação vigente em Portugal, nomeadamente no Decreto-Lei 163/2006 de 8 de agosto, onde foram consideradas as seguintes variáveis: percursos pedonais; escadarias em rampa; rampas; passagens de peões de superfície; passagens de peões desniveladas; outros espaços de circulação e permanência de peões; espaços para estacionamentos de viaturas; paragens de autocarros.
Foi adaptada a classificação de acessibilidade de Rovira-Beleta \& Folch (2007)(7) para a operacionalização de cada uma das variáveis, tendo por base o olhar e os conhecimentos da enfermagem para a deambulação: não acessível; acessível com ajuda; acessível com dificuldade; acessível sem dificuldade e não aplicável. Também foi avaliada a variável "caraterísticas dimensionais da via pública".

Para a aproximação ao campo foi realizada uma visita guiada aos principais acessos por representantes da Câmara e para a recolha de dados foram batidas a pé as 31 ruas, num total de $15 \mathrm{~km} 208 \mathrm{~m}$, sendo efetuadas as medidas necessárias para cada categoria avaliada, com fita métrica.

Os princípios éticos foram cumpridos através de um parecer favorável por parte da Comissão de Ética da Escola Superior de Enfermagem do Porto já existente e foram ainda realizadas várias reuniões com os representantes da Câmara Municipal de Vila Nova de Famalicão, com objetivo de explicar a organização do trabalho e determinar as ruas alvo de avaliação para a investigação. Como a investigação não envolve diretamente pessoas, mas sim a via pública, substituiuse o nome das ruas por códigos, por forma a assegurar a confidencialidade, no entanto foi entregue ao município uma ficha descritiva de cada rua.

Os dados foram tratados estatisticamente no programa de software IBM SPSS, versão 20.0 e através da estatística descritiva (cálculo de frequências absolutas e relativas; medidas de tendência central (média e mediana) e o cálculo de medidas de dispersão, através dos valores mínimos e máximo e do desvio padrão).

\section{RESULTADOS}

A variação de comprimento das dimensões da via pública foi no mínimo $78 \mathrm{~m}$ e no máximo $700 \mathrm{~m}$, sendo a média da dimensão das ruas de $250,13 \mathrm{~m}$. Contudo, a dispersão é grande, uma vez que o desvio padrão é igual a 157,205.

"As áreas urbanizadas devem ser servidas por uma rede de percursos pedonais, designados de acessíveis, que proporcionem o acesso seguro e confortável das pessoas com mobilidade condicionada a todos os pontos relevantes da sua estrutura ativa"(1), satisfazendo os critérios das respetivas secções.

Dos percursos pedonais analisados, $75,8 \%$ permitem o acesso e permanência de uma pessoa em cadeira de rodas, bem como o alcance frontal e lateral aos objetos dispostos na via, no entanto $22,6 \%$ dos percursos não o permite. Quanto à obstrução de um ou mais lados, $85,5 \%$ dos percursos são considerados acessíveis sem dificuldade, sendo que $12,9 \%$ são não acessíveis.

Uma pessoa em cadeira de rodas é capaz de realizar uma mudança de direção sem ser necessário deslocamento em 37,1\% dos percursos, mas em $61,3 \%$ não. Quando é necessário deslocamento, 58,1\% dos percursos permitem-no, mas 40,3\% não.

Os objetos salientes devem cumprir requisitos, relativamente à sua projeção em paredes; em pilares/colunas e outros objetos. Em 3,2\% dos percursos 
foram observados outros objetos salientes, que não cumpriam os requisitos estipulados, sendo considerados não acessíveis.

As mudanças de nível abruptas devem ser evitadas e, caso existam, devem ter um tratamento adequado à sua altura(1). Assim, 82,3\% dos percursos cumprem os requisitos, enquanto que $16,1 \%$ não cumprem, sendo não acessíveis.

Relativamente ao estado do piso, a generalidade dos percursos apresenta um estado do piso (79\%) e reflectância $(96,8 \%)$ acessível sem dificuldade. A inclinação dos pisos foi avaliada na direção do percurso e na direção transversal. Assim, na direção do percurso 83.9\% é acessível sem dificuldade e na direção transversal, $87,1 \%$ é considerada acessível.

Quanto aos elementos vegetais, 48,4\% das caldeiras das árvores existentes nos percursos pedonais são acessíveis sem dificuldade e os espaços no piso são igualmente acessíveis sem dificuldade em $79 \%$ dos percursos. As áreas adjacentes aos percursos são acessíveis sem dificuldade em 54,8\%, acessível com ajuda em 3,2\% e outros 3,2\% não acessíveis.

Dos 62 percursos pedonais avaliados, 80,6\% são acessíveis sem dificuldade relativamente à existência da sinalização e 16,1\% não acessíveis. A sinalização é legível em $80,6 \%$ dos percursos. Um dos percursos apresentava obras, que estavam corretamente identificadas, sendo por isso considerado acessível sem dificuldade - $3.2 \%$.

Sobre o cumprimento das condições de acessibilidade das rampas, a lei afirma que estas devem ter a menor inclinação possível e ainda obedecer a certos parâmetros (1). Das 3 rampas existentes nos percursos avaliados, 2 delas são acessíveis relativamente à inclinação, largura, dimensões da plataforma horizontal de descanso e existência de corrimãos, sendo que a outra não o é. Acerca da sinalização táctil, nenhuma das rampas é possuidora de tal característica.

Sobre as passagens de peões de superfície, estas são essenciais na continuidade dos percursos pedonais(8). As 79 passadeiras observadas apresentam a maior percentagem no indicador acessível sem dificuldade, contudo uma percentagem considerável em dimensões muito relevantes não é acessível ou quando o é, é com dificuldade ou ajuda. 59,5\% das passagens de peões apresentam a altura de lancil acessível sem dificuldade, $11,4 \%$ acessível com dificuldade, 3,8\% acessível com ajuda e 25,3\% não acessível. Na inclinação da direção da passagem, 69,6\% são acessíveis sem dificuldade, 2,5\% acessível com dificuldade, 1,3\% acessível com ajuda e $26,6 \%$ não acessível. $\mathrm{Na}$ inclinação na direção do passeio, 70,9\% são acessíveis sem dificuldade, 2,5\% acessível com dificuldade, 1,3\% acessível com ajuda e 25,3\% não acessível. Em relação à inclinação do piso, $88.6 \%$ são não aplicáveis e $11,4 \%$ são consideradas acessíveis sem dificuldade. Sobre a largura dos separadores centrais, 15,1\% são considerados acessíveis sem dificuldade, 2.5\% não acessíveis, 82,3\% correspondem a não aplicável, visto que não apresentavam separadores centrais. Uma vez que nenhuma possui semáforos, todas as passadeiras são inacessíveis nesta dimensão para invisuais, já que não existe qualquer emissão de sinal sonoro, não promovendo a segurança aquando da travessia. Uma grande percentagem das passagens não apresenta zona de interceção com os separadores centrais, daí que a largura foi avaliada em não aplicável.

Em muitas das situações não é possível definir percursos acessíveis que liguem todos os espaços fundamentais do ambiente edificado, ditando que 0 acesso por automóvel seja a única forma de garantir o mesmo(8). Assim, é essencial que existam de forma distribuída, lugares reservados destinados a pessoas com mobilidade condicionada.

Dos percursos avaliados, em $12,9 \%$ existe o número de locais reservados previstos por lei, enquanto que em $75,8 \%$ esta condição não se verifica.

Sobre a largura útil, $32 \%$ respeitam as medidas estipuladas, sendo que $68 \%$ corresponde à percentagem de lugares que não são acessíveis. $64 \%$ dos lugares apresentam o comprimento útil estipulado, já $36 \%$ não são cumpridores. Em relação à existência da faixa lateral, $8 \%$ apresentam esta característica, no entanto $92 \%$ não apresentam, sendo não acessíveis. Quando à localização e ao local de entrada/saída de viaturas, 92\% são considerados acessíveis sem dificuldade e $8 \%$ não acessíveis. Acerca dos limites, $88 \%$ são considerados acessíveis sem dificuldade, enquanto que $12 \%$ não são acessiveis. $76 \%$ dos lugares apresentam sinalização horizontal e $24 \%$ não. $96 \%$ apresentam sinalização vertical e $4 \%$ não.

Acerca das paragens de autocarros, a maioria não apresenta obstáculos que possam tornar o espaço inacessível, bem como apresentam uma área adjacente para embarque igualmente livre de obstáculos $(78,9 \%$ acessível sem dificuldade). Também a ligação da zona de embarque com as zonas pedonais é na grande maioria acessível.

Sobre a informação legível existente, em $52,6 \%$, ou seja, em 10 das paragens não existe qualquer tipo de informação, sendo que nos $47,4 \%$, ou seja, 9 paragens a informação o é. Das 5 paragens com abrigo, todas elas cumprem o estipulado para um abrigo acessível e das 14 com placa informativa, em $71,4 \%$ a placa não obstrui o passeio, no entanto em $28,4 \%$ obstrui.

\section{DISCUSSÃO}

A pesquisa realizada teve por base a compreensão das condições de acessibilidade na via pública e como é que os ambientes externos ao edificado contribuem para a inclusão social das pessoas com mobilidade condicionada, tendo em vista o papel do enfermeiro de reabilitação como chave na melhoria da acessibilidade na via pública para estas pessoas.

A inacessibilidade arquitetónica existente nas cidades contribui para que a pessoa em cadeira de rodas tenha uma maior dificuldade de locomoção e liberdade de movimentação, bem como sentimentos de exclusão e isolamento social(9).

Um estudo, que tinha como objetivo analisar itinerários da vila de Cascais(10), tendo em conta o processo de implementação política, também avaliou os percursos 
pedonais, de acordo com a classificação de acessibilidade de Rovira-Beleta \& Folch (2007)(7), sendo concomitante com alguns resultados do presente estudo, nomeadamente o facto da largura, o estado do piso e a inclinação serem maioritariamente acessíveis.

Relativamente às zonas de manobra, também o estudo de Fernandes (2014)(11) avaliou esta dimensão maioritariamente como não acessível, visto que nos troços observados só é possível realizar mudanças de direção de $90^{\circ}$ e mudanças de direção em “ $T$ ".

Um outro estudo denominado "Acessibilidade ao Campus da Cidade Universitária da Universidade de Lisboa, pela Comunidade Académica Com Mobilidade Condicionada: Avaliação e Proposta de Melhoria" de Simões, Costa, Rocha, Abrantes \& Guimarães (2016)(12) identificou a existência de barreiras, passeios estreitos e os passeios que não eram rebaixados não eram detentores dos pré-requisitos, ou seja, apresentavam um piso bastante irregular e com uma fraca manutenção da calçada, com pedras soltas no pavimento, factos observados na nossa investigação. 0 mesmo estudo também observou inúmeros objetos salientes, nomeadamente caixotes do lixo, bancos de jardim, troncos de árvores cortados e a falta de sinalização sonora no atravessamento de passadeiras. Embora em pequena percentagem, estes fenómenos também são visíveis nos percursos pedonais observados no presente estudo.

Quanto à existência de sinalização e sua legibilidade, os percursos pedonais são maioritariamente acessíveis, mas é necessário refletir no facto de que os invisuais não conseguem aceder a esta sinalização. 0 trabalho de Simões, Costa, Rocha, Abrantes \& Guimarães (2016)(12) apresenta como solução a colocação de placas em braille ou pontos de referência, bem como aplicações para telemóveis que ajudem a identificar e localizar os serviços públicos.

Relativamente às passagens de peões de superfície, os dados observados no nosso estudo parecem-se com os dados observados por Teixeira (2010)(10). A altura do lancil e a inclinação são maioritariamente não acessíveis ou acessíveis com ajuda ou dificuldade. $\mathrm{Na}$ presente investigação, os obstáculos nas passagens de peões não foram considerados para avaliação, no entanto estes existiam em algumas delas, sendo que $7,9 \%$ dos percursos observados por Teixeira (2010)(10) apresentam obstáculos que põem em causa a acessibilidade.

Teixeira (2010)(10) também observou que as rampas existentes nos percursos não cumprem os requisitos de acessibilidade, sendo classificadas como não acessíveis, por não apresentarem corrimãos e terem uma inclinação desfavorável, tal como no presente estudo. Pagliuca, Freitag, Aragão \& Almeida (2007)(13), num estudo com o objetivo de pesquisar as barreiras físicas encontradas pelas pessoas com deficiência em quatro hospitais de uma dada área, verificaram que em 3 deles, as rampas também não possuíam corrimãos. Pinto e Pires (2015)(14) analisaram a acessibilidade escolar, avaliando 3 passagens, em que apenas uma apresentava o lancil rebaixado e outra a inclinação do pavimento na direção da travessia e na direção do lancil dentro dos parâmetros pretendidos. É de realçar que também nenhuma das rampas observadas apresenta semáforos, nem emissão de sinais sonoros, tornando-as inacessíveis a pessoas invisuais. Apolo (2010)(15), no seu estudo que tinha como objetivo analisar a mobilidade das pessoas com deficiência em 3 zonas urbanas de Lisboa, detetou ainda a inexistência de passeios rebaixados junto às travessias de peões ou, em certos casos, quando existe encontra-se malexecutado. Ou seja, também a altura do lancil é inacessível.

Ainda no estudo supracitado, foi observada a inexistência de estacionamentos reservados a deficientes e os únicos existentes encontravam-se apenas nos parques de estacionamento subterrâneos e no parque do Centro Comercial, todos eles pagos. Tal facto corrobora o presente estudo, onde a maioria dos percursos não apresenta um número de lugares reservados suficiente, dificultando o acesso das pessoas com mobilidade condicionada aos serviços existentes nas ruas, necessários à integridade da cidadania.

No que concerne às paragens de autocarro, também no estudo de Teixeira (2010)(10), a generalidade das paragens de autocarros é maioritariamente acessível, dados que corroboram os obtidos no presente estudo.

No estudo de Pereira, Martins, M Schoeller, Gomes, Laredo- Aguilera, Ribeiro \& Cunha (2018)(16), cujo o objetivo é compreender as respostas das autarquias locais para abolir barreiras arquitetónicas para pessoas com mobilidade condicionada, a opinião dos presidentes de junta sobre o cumprimento das disposições legais do Decreto-Lei 163/2006 é concomitante com o presente estudo nas seguintes dimensões: revestimento do piso dos passeios com uma superfície estável, durável e firme (38,1\%); o acesso frontal/lateral para o abrigo apresentar uma largura $\geq 0,80$ m e não apresentar obstáculos (42,9\%).

Partindo desta análise, depreende-se que apenas uma parte da população é capaz de utilizar os percursos com alguma segurança, visto que para tal é necessário que a pessoa tenha agilidade, equilíbrio, cognição, coordenação, endurance, os cinco sentidos preservados e capacidade de processamento sensorial(17). Fica assim demonstrada a necessidade de os enfermeiros especialistas em enfermagem de reabilitação repensarem a importância da sua intervenção para alertar as autoridades que decidem sobre as acessibilidades, até porque as pessoas têm necessidade e vivem nestes espaços.

\section{CONCLUSÃO}

As condições de acessibilidade influenciam diretamente o modus operandi de todas as pessoas, principalmente o das pessoas com mobilidade condicionada, sendo de extrema importância compreender de que forma é que a legislação portuguesa está a ser implementada em termos de acessibilidade pública.

As ruas analisadas são ruas estratégicas e artérias principais da cidade. Dos 62 percursos pedonais, 14 não permitem o acesso e permanência de uma pessoa em cadeira de rodas. Isto significa que um quarto dos 
percursos pedonais é inibidor da participação social ativa das pessoas com mobilidade condicionada. Assim, estes resultados provam que o cumprimento do Decreto-Lei 163/2006 ainda se encontra muito longe de ser alcançado. No entanto, é de valorizar que, após a conclusão da colheita de dados, um dos percursos pedonais iniciou obras no passeio.

Os resultados evidenciam que, dos percursos analisados, 10 apresentam mudanças de nível abrupto ao longo da via, que não são compensadas por rampa, tornando-os inacessíveis.

As passagens de peões de superfície, fundamentais para a continuidade dos percursos pedonais, apresentam características inacessíveis em grande percentagem, nomeadamente a altura do lancil, a inclinação na direção da passagem e do passeio, bem como o facto de nenhuma delas apresentar semáforos.

Praticamente metade dos percursos avaliados não apresenta lugares de estacionamento reservados a pessoas com mobilidade condicionada e a pequena percentagem existente não cumpre critérios fundamentais, como a largura útil e a existência da faixa lateral.

Neste sentido, conclui-se que os percursos observados apresentam inúmeras barreiras arquitetónicas, dificultando a mobilidade e acessibilidade.

Tal fato, leva-nos a afirmar que a cidade precisa de uma intervenção para as pessoas com mobilidade condicionada passarem a ter uma cidade amigável.

A metodologia quantitativa funcionou como elemento fundamental na obtenção dos dados, simplificando a compreensão da análise dos mesmos.

O tamanho da amostra não permite generalizar os resultados, uma vez que é representativo apenas de uma Autarquia, o que sugere ser necessário proceder a mais estudos noutros municípios para melhor se compreender o fenómeno. Esta temática é ainda muito pouco estudada em Portugal, havendo pouca evidência de outros estudos. Seria interessante replicar esta investigação noutras Autarquias, podendo obter-se uma maior amostragem e assim identificar as barreiras arquitetónicas existentes noutros municípios para posteriormente se proceder à sua eliminação.

0 enfermeiro especialista em enfermagem de reabilitação poderá ser um elo de ligação entre o contexto comunitário, as Autarquias e as pessoas com mobilidade condicionada, permitindo a identificação e orientação para a abolição das barreiras arquitetónicas, dado que estas comprometem a participação e a inclusão social da pessoa com mobilidade condicionada.

\section{REFERÊNCIAS BIBLIOGRÁFICAS}

1. DECRETO-LEI n. ${ }^{\circ}$ 163/2006. D.R. I Série. No 152 (2006-08-08). pp. 5670-5689

2. ORDEM DOS ENFERMEIROS - Regulamento dos Padrões de Qualidade dos Cuidados Especializados em Enfermagem de Reabilitação - Regulamento aprovado na Assembleia Geral Extraordinária de 22 de Outubro de 2011; [Consult. 18 out. 2017]. Disponível na Internet: <URL: http://www.ordemenfermeiros.pt/colegios/documents/pqceere abilitacao.pdf>
3. INE. Censos 2011 Resultados Definitivos - Portugal. (2012)

4. PEREIRA, R. (2018). “Autarquias Inclusivas? O/a enfermeiro/a de Reabilitação na Eliminação de barreiras Arquitetónicas". Escola Superior de Enfermagem do Porto, Porto. Disponível em: <https://comum.rcaap.pt/bitstream/10400.26/23040/1/DISSER TA\%C3\%87\%C3\%830 \%20DEFINITIVA.pdf>; isEP?

5. BORDALO, Ana. Urbanismo e inclusão - a perspetiva da acessibilidade e mobilidade para todos. Malha Urbana. 2012. Disponível na Internet: <URL: http://recil.grupolusofona.pt/bitstream/handle/10437/2990/21 92.pdf?sequence $=>$

6. PEREIRA, A. (2019). "Uma Cidade Amigável para as Pessoas Com Mobilidade Condicionada". Escola Superior de Enfermagem do Porto, Porto. Disponível em < https: / /comum.rcaap.pt/bitstream/10400.26/29468/1/DISSERT A\%c3\%87\%c3\%830\%20DE\%20MESTRADO\%20ANA\%20PEREIRA\%20ESE P\%20EP4212.pdf>

7. ROVIRA-BELETA, Enrique e FOLCH, Ana. Descripción de La Guía. Guía de la Barcelona acessible. 2007. [Consult. 18 out. 2017]. Disponível na Internet: <URL: http://www.vienaeditorial.com/barcelonaaccesible/index.htm>

8. TELES, P. Loures Acessível - Manual de Orientações Técnicas Acessibilidade e Mobilidade. (2014). ISBN 978-972-9142-49-9. [Consult. 7 nov. 2017]. Disponível na Internet: <URL: http://loures.bloco.org/sites/default/files/manual_tecnico_ace ssibilidade_e_mobilidade.pdf $>$

9. CARVALHO, ZM Figueiredo., FONTENELE MORAES, P de O., AGOSTINHO ROLIM, G., DE ALMEIDA, PC. (2008) A acessibilidade em cadeira de rodas nas clínicas e consultórios de neurologia e neurocirurgia de Fortaleza - Brasil. Enfermería Global. 14, 2008

10. TEIXEIRA, D. (2010). Igualdade de Oportunidades: Um Olhar Sobre as Barreiras Arquitetónicas à Acessibilidade. Universidade Técnica de Lisboa - Instituto Superior de Ciências Sociais e Políticas, Lisboa. [Consult. 18 out. 2017]. Disponível na Internet: <URL: http://hdl.handle.net/10400.5/3018>

11. FERNANDES, T. (2014). Conformidade do espaço urbano para pessoas com mobilidade reduzida. Universidade do Minho - Escola de Engenharia, Minho. [Consult. 7 nov. 2017]. Disponível na Internet: <URL: http://hdl.handle.net/1822/36430>

12. SIMÕES, J.M., COSTA, E.M., ROCHA, J., ABRANTES P., GUIMARÃES, P. (2015/2016). Acessibilidade ao campus da cidade universitária da universidade de Lisboa, pela comunidade académica com mobilidade condicionada: Avaliação e proposta de melhoria. Seminário em Planeamento e Gestão

13. PAGLIUCA, Lorita Marlena Freitag; ARAGAO, Antônia Eliana de Araújo e ALMEIDA, Paulo César. Acessibilidade e deficiência física: identificação de barreiras arquitetónicas em áreas internas de hospitais de Sobral, Ceará. Rev. esc. enferm. USP [online]. 2007, vol.41, n.4, pp.581-588. ISSN 0080-6234. [Consult. 18 out. 2017]. Disponível na Internet: <URL: http://dx.doi.org/10.1590/S0080-62342007000400007>

14. PINTO S., PIRES M. R. (2015). Acessibilidade escolar: o caso da Escola Secundária Pinheiro e Rosa em Faro. Instituto Politécnico de Leiria. Leiria. Cconsult. 7 nov. 2017]. Disponível na Internet: <URL: http://hdl.handle.net/10400.1/10107>

15. APOLO, A.P.V.V. (2010). Análise da Mobilidade de Pessoas com Deficiência - Estudo de Caso. Instituto Superior de Engenharia de Lisboa, Lisboa. [Consult. 18 out. 2017]. Disponível na Internet: <URL: http://hdl.handle.net/10400.21/245>

16. PEREIRA, R.; MARTINS, M SCHOELLER S.D., Gomes, B.P., LAREDOAGUILERA, J. A., RIBEIRO, I., CUNHA, P. (2018). As autarquias e a promoção da acessibilidade arquitetónica. Revista de Enfermagem. Referência. 2018:29-38. [Consult. 12 set. 2018]. Disponível na Internet: https: //doi.org/10.12707/RIV18022>

17. SIMÃO, J.M.P. (2015). Mobilidade e acessibilidade no centro de Cascais. Universidade Lusíada de Lisboa, Lisboa. [Consult. 12 set. 2018]. Disponível na Internet: <URL: <http://repositorio.ulusiada.pt/bitstream/11067/2235/1/mia_j orge_simao_dissertacao.pdf> 